\title{
Naturally produced type I IFNs enhance human myeloid dendritic cell maturation and IL-12p70 production and mediate elevated effector functions in innate and adaptive immune cells
}

\author{
Annette E. Sköld ${ }^{1,2}$ (1) - Till S. M. Mathan ${ }^{1}$. Jasper J. P. van Beek ${ }^{1} \cdot$ Georgina Flórez-Grau ${ }^{1}$. \\ Michelle D. van den Beukel ${ }^{1}$. Simone P. Sittig ${ }^{1}$. Florian Wimmers ${ }^{1}$. Ghaith Bakdash ${ }^{1,4}$. Gerty Schreibelt ${ }^{1}$. \\ I. Jolanda M. de Vries ${ }^{1,3}$
}

Received: 23 October 2017 / Accepted: 6 July 2018 / Published online: 13 July 2018

(c) The Author(s) 2018

\begin{abstract}
There has recently been a paradigm shift in the field of dendritic cell (DC)-based immunotherapy, where several clinical studies have confirmed the feasibility and advantageousness of using directly isolated human blood-derived DCs over in vitro differentiated subsets. There are two major DC subsets found in blood; plasmacytoid DCs (pDCs) and myeloid DCs (mDCs), and both have been tested clinically. CD1 $\mathrm{c}^{+} \mathrm{mDCs}$ are highly efficient antigen-presenting cells that have the ability to secrete IL-12p70, while pDCs are professional IFN- $\alpha$-secreting cells that are shown to induce innate immune responses in melanoma patients. Hence, combining mDCs and pDCs poses as an attractive, multi-functional vaccine approach. However, type I IFNs have been reported to inhibit IL-12p70 production and mDC-induced T-cell activation. In this study, we investigate the effect of IFN- $\alpha$ on $\mathrm{mDC}$ maturation and function. We demonstrate that both recombinant IFN- $\alpha$ and activated pDCs strongly enhance mDC maturation and increase IL-12p70 production. Co-cultured mDCs and pDCs additionally have beneficial effect on NK and NKT-cell activation and also enhances IFN- $\gamma$ production by allogeneic T cells. In contrast, the presence of type I IFNs reduces the proliferative T-cell response. The mere presence of a small fraction of activated pDCs is sufficient for these effects and the required ratio between the subsets is non-stringent. Taken together, these results support the usage of $\mathrm{mDCs}$ and $\mathrm{pDCs}$ combined into one immunotherapeutic vaccine with broad immunostimulatory features.
\end{abstract}

Keywords Dendritic cells $\cdot$ Cytokines $\cdot$ Cell activation $\cdot$ Tumor immunity $\cdot$ Vaccination

Electronic supplementary material The online version of this article (https://doi.org/10.1007/s00262-018-2204-2) contains supplementary material, which is available to authorized users.

I. Jolanda M. de Vries

Jolanda.deVries@radboudumc.nl

1 Department of Tumor Immunology, Radboud Institute for Molecular Life Sciences, Radboudumc, Geert Grooteplein 26/28, 6525 GA Nijmegen, The Netherlands

2 Department of Oncology-Pathology, Cancer Center Karolinska, Karolinska Institutet, Stockholm, Sweden

3 Department of Medical Oncology, Radboud Institute for Molecular Life Sciences, Radboudumc, Nijmegen, The Netherlands

4 Present Address: Allergic Inflammation Discovery Performance Unit, Respiratory Therapy Area, GlaxoSmithKline, Stevenage, United Kingdom

\author{
Abbreviations \\ $\mathrm{CM} \quad$ Conditioned medium \\ $\mathrm{mDC} \quad$ Myeloid dendritic cell \\ moDC Monocyte-derived dendritic cell \\ pDC Plasmacytoid dendritic cell \\ pR Protamine-RNA \\ rIL-12 Recombinant interleukin-12p70
}

\section{Introduction}

Dendritic cells (DCs) are professional antigen-presenting cells, best known for their ability to activate and polarize naïve $\mathrm{T}$ cells [1]. These characteristics have made DCs an interesting target in vaccine development, and several different protocols have been tested clinically [2]. A classical source of DCs used in clinical studies are monocyte-derived DCs (moDCs) [3]. However, recent progress within the field has made it feasible to use naturally circulating blood DCs 
in therapeutic vaccination against cancer. Both pDCs and $\mathrm{CD} 1 \mathrm{c}^{+} \mathrm{mDCs}$ have been tested clinically in cancer patients and antigen-specific T-cell responses and prolonged overall survival have been achieved [4, 5]. Using natural blood DCs in cell-based immunotherapy is more beneficial compared to moDCs in many aspects, such as reduced ex vivo culture time, less exhaustion, and high migratory capacity [6].

In general, mDCs are displaying "classical" DC features, such as efficient antigen uptake and presentation, and have the ability to initiate Thelper (Th) 1 responses by production of IL-12p70 [7]. Stimulated pDCs release high quantities of IFN- $\alpha$, a group of type I IFNs important in responses towards viral infections [8] and an important feedback loop to enhance cellular responses towards the detection of nucleic acids [9]. Type I IFNs also have a stimulating effect on innate immune cells, such as NK cells and NKT cells, and these responses are in turn important to identify and eliminate mutated autologous tumor cells [10]. Hence, a vaccine based on the combination of mDCs and pDCs would have the ability to initiate both adaptive and innate anti-tumor immune responses. At the time of their discovery, DCs were referred to as "nature's adjuvant" [11], and the two subsets might even have additive effects on each other when matured together. Indeed, the responsiveness to TLR ligands has been shown to increase for both subsets when cultured together [12], and IFN- $\alpha$ has been shown to upregulate additional TLRs on both mDCs and pDCs [13]. During viral infection, $\mathrm{pDCs}$ are important stimulators of $\mathrm{mDCs}$, which in turn enhances anti-viral responses [14]. Also, in a murine tumor vaccination model, antigen-specific $\mathrm{T}$-cell responses were increased when mDCs and pDCs were activated together rather than separately [15].

On the other hand, there is a risk that $\mathrm{mDC}-\mathrm{pDC}$ crosstalk would have a negative impact as a combined vaccine product. Type I IFNs have been reported to have dampening effects on both immune and non-immune cells [8, 16]. Although IFN- $\alpha$ is needed in low levels to induce IL-12 production [17], some studies have indicated a negative effect on human mDCs and moDCs. The release of IL- 12 has been reported to be inhibited by high doses of type I IFNs [18-20]. However, several studies have shown an increase of IL-12 production from human [21-23] and murine [13, $17,24]$ DCs in the presence of IFN- $\alpha$.

In present study, we investigate the responses of human blood-derived DC subsets either treated with recombinant IFN- $\alpha$ or IL-12p70 or co-cultured at various ratios. The production of cell type-specific cytokines and the expression of maturation markers are evaluated. Additionally, we investigate how these cultures affect both innate and adaptive immune cells. As stimulus, we use protamine-RNA complexes (pR), a previously described TLR7/8 agonist that induces high levels of both IL-12p70 and IFN- $\alpha$ in mDCs and pDCs, respectively [25-28]. This will prevent possible artifact effects previously detected upon combination of different TLR ligands [29] and better resemble the clinical studies on $\mathrm{mDCs}$ and pDCs that are being performed with this stimulus (NCT02574377, NCT02993315, and NCT02692976). We demonstrate that IFN- $\alpha$ matures mDCs and increases IL-12p70 production. In addition, we demonstrate that $\mathrm{pR}$-induced $\mathrm{mDC}$ maturation is dependent on type I IFN signaling and that co-cultured DCs increase both innate immune cell and T-cell activations, but dampen the proliferative response of T cells. Our study explores the potential of crosstalk between different subsets of human blood-derived DC subsets and clarifies why contradictory effects of type I IFNs previously have been reported in literature. This study supports the combined usage of CD1c $\mathrm{c}^{+}$ $\mathrm{mDCs}$ and $\mathrm{pDCs}$ as a cellular anti-cancer immunotherapy, combining the beneficial effects of both subsets into one potent treatment modality.

\section{Materials and methods}

\section{Reagents}

DCs were activated with TLR7/8 ligand imidazoquinoline

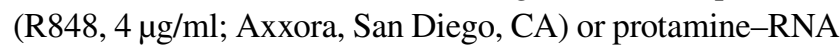
complexes (pR, $15 \mu \mathrm{g} / \mathrm{ml}$ ) formed in water as previously described [25] by mixing protamine (Protaminehydrochloride MPH $5000 \mathrm{IE} / \mathrm{ml}, 0.5 \mu \mathrm{g} / \mathrm{ml}$; Meda Pharma BV, Amstelveen, the Netherlands) and gp100 mRNA $(0.5 \mu \mathrm{g} / \mathrm{ml})$ in a 2:1 ratio. Recombinant IFN- $\alpha 2 \mathrm{a}\left(\right.$ Roferon $^{\circledR}-\mathrm{A}, 1 ; 10$; and $100 \mathrm{ng} / \mathrm{ml}$, corresponding to ca $1.35 \times 10^{2}-1.35 \times 10^{4} \mathrm{UI} / \mathrm{ml}$; Roche, Basel, Switzerland) and IL-12p70 (0.2-2 ng/ml; BD Biosciences, San Jose, CA) were used to stimulate mDCs and pDCs, respectively, and recombinant IL-3 $(10 \mathrm{ng} / \mathrm{ml}$; Cellgenix, Freiburg, Germany) was used as a survival factor for unstimulated pDCs.

To capture intracellular cytokines for flow cytometry, Brefeldin A (10 $\mu \mathrm{g} / \mathrm{ml}$; Sigma-Aldrich, St Louis, MO) was added to the cultured cells 4 or $12 \mathrm{~h}$ before analysis.

Isolated PBLs or T cells were activated with Dynabeads human T-activator CD3/CD28 (anti-CD3/anti-CD28 beads, $0.25 \times 10^{6}$ beads $/ \mathrm{ml}$; Life Technologies, Carlsbad, CA).

\section{Cell isolation and culture}

PBMCs were isolated from buffy coats (Sanquin, Nijmegen, The Netherlands) by ficoll density centrifugation (Lymphoprep; Axis-Shield PoC AS, Oslo, Norway). Microbead isolation kits $\left(\mathrm{BDCA} 1^{+} \mathrm{DC}\right.$ and $\mathrm{BDCA} 4^{+} \mathrm{DC}$ isolation kits; Miltenyi Biotec, Bergisch-Gladbach, Germany) were used to isolate $\mathrm{CD} 1 \mathrm{c}^{+} \mathrm{mDCs}$ and $\mathrm{pDC}$ from PBMCs. For mDCs, $\mathrm{CD}_{14}{ }^{+}$cells were depleted using CD14 microbeads (Miltenyi Biotec) and prior pDCs isolation, PBLs were 
prepared from PBMCs by plastic adherence for $1 \mathrm{~h}$ in RPMI (Life Technologies) supplemented with $2 \%$ human serum (Sanquin, Nijmegen, The Netherlands) and $0.5 \%$ antibiotic antimycotic (PAA laboratories, Pasching, Austria). Pan-T cells were negatively selected from PBLs using microbead isolation (Miltenyi Biotec).

Purified cells were cultured at $0.5 \times 10^{6}$ cells $/ \mathrm{ml}$ in X-VIVO-15 medium (Lonza, Basel, Switzerland) supplemented with $2 \%$ human serum. For the co-cultures, autologous mDCs and pDCs were mixed in ratios of $1: 1$ and 5:1, with the total cell concentration kept constant between the co-culture conditions and single-cultured cells.

\section{Type I IFN blocking experiment}

Cells were cultured with a cocktail of three blocking antibodies: anti-IFN- $\alpha(5000 \mathrm{NU} / \mathrm{ml})$, anti-IFN- $\beta$ (5000 NU/ $\mathrm{ml}$ ), and anti-IFNAR1 $(20 \mathrm{mg} / \mathrm{ml})$ (all from PBL Biomedical Laboratories, Piscataway, NJ, USA). Samples were pretreated with the IFN blocking cocktail for $1 \mathrm{~h}$ at $37^{\circ} \mathrm{C}$ before addition of stimuli.

\section{ELISA}

Cytokines were measured in cell culture supernatants taken at indicated time points and the levels of IL-12p70, IFN- $\gamma$ (both from Thermo Scientific, Waltham, MA), IFN- $\alpha$ (Bender Medsystems, Vienna, Austria), and TNF- $\alpha$ (BD Biosciences) were assessed with sandwich ELISA.

\section{Flow cytometry}

Freshly isolated $\mathrm{mDC}$ and $\mathrm{pDC}$ were stained with the following primary $\mathrm{mAbs}$ to evaluate phenotype: anti-CD14-FITC (Dako, Glostrup, Denmark), anti-BDCA1-PE (Miltenyi Biotec), anti-BDCA-2-Pe-Cy7 (Biolegend, San Diego, CA) and anti-CD20-APC (eBioscience). The purity of freshly isolated $\mathrm{T}$ cells was determined with mAbs anti-CD20-FITC, anti-CD3-PE, and anti-CD56-APC (all BD Biosciences). DC maturation was evaluated with mAbs anti-CD80-PE, anti-CD86-APC, (both BD Biosciences), and anti-CD40PE (Immunotech, Marseille, France). In DC co-cultures, mDCs and pDCs were identified by mAbs anti-CD11cFITC (BD Biosciences) and anti-BDCA2-PE-Cy7 (Biolegend). The cell subsets in PBLs were identified with $m A b s$ anti-CD56-APC and anti-CD3-PE-Cy7 (eBiosciences) and their activation was determined with mAbs anti-CD69-FITC and anti-IFN- $\gamma$-BV421 (both from BD Biosciences). For the IFN- $\gamma$ stainings, fluorescence minus one controls were made on positive controls using either a concentration-matched anti-mouse IgG1-BV421 isotype control (eBioscience) or no $\mathrm{mAb}$ at all.
For cultured cells, viability was assessed with Fixable Viability Dye eFluor 780 (eBioscience). In the proliferation assays, PBLs or T cells were labeled with carboxyfluorescein diacetate succinimidyl ester (CFSE, $5 \mu \mathrm{M}$; Life Technologies). To perform intracellular cytokine staining (ICS), the cells were fixed and permeabilized using a cytofix/cytoperm kit (BD Biosciences).

The cells were acquired on a FACSVerse (BD Biosciences) and the data were analyzed with FlowJo Software (TreeStar Inc., Ashland, OR). Duplicate events were excluded by FCS-A-FCS-H gating. Lymphocytes or DCs were identified by FCS-SSC and subsequently by phenotypic markers.

\section{Mixed lymphocyte reaction}

T-cell proliferation or innate cell activation was determined in mixed lymphocyte reactions (MLRs). DCs were activated overnight in round-bottomed 96-well plates. In some assays, fresh medium was added to the cultures and the cells were pelleted by centrifugation. The medium was discarded and the procedure was repeated two more times. Allogeneic PBLs or T cells were added in a 10:1 or 5:1 ratio, respectively. PBL activation was evaluated after overnight co-culture and T-cell proliferation after 5 days of co-culture.

\section{Statistical analyses}

Statistical relevance was calculated in GraphPad Prism (v5.0; San Diego, CA). To perform multiple variance analyses, ANOVA with Bonferroni's multiple comparison test was applied. Wilcoxon matched-pairs signed rank tests were performed for paired analyses.

\section{Results}

\section{Recombinant IFN- $a$ increases the production of IL-12p70 by $\mathrm{mDCs}$ and increases $\mathrm{pR}$-induced maturation}

Detection of nucleic acids by endosomal TLRs induces low levels of type I IFN, which in an autocrine manner enhances the response to the ligand [13, 30], and RNA-based adjuvants have clinically been shown to induce type I IFNmediated anti-tumor responses $[9,31]$. We have previously shown that the TLR7/8 ligand protamine-RNA (pR) induces maturation and release of high levels of IL-12p70 and IFN- $\alpha$ by $\mathrm{mDCs}$ and pDCs, respectively [25]. We, therefore, first investigated the involvement of type I IFN signaling in $\mathrm{pR}$ mediated DC maturation. DCs were pre-treated with a cocktail of type I IFN blocking antibodies before addition of $\mathrm{pR}$ complexes and upregulation of the maturation marker CD80 
was investigated after overnight culture. Type I IFN signaling was required for $\mathrm{pR}$-mediated $\mathrm{mDC}$ maturation, but not for pDCs (Fig. 1a, b).

Next, we investigated how the DC-specific cytokine production was affected upon addition of recombinant cytokines. To represent both low- and high-producing donors as well as varying DC concentrations, a range between 0.2 and $2 \mathrm{ng} / \mathrm{ml}$ of recombinant IL-12p70 (rIL-12) and 1-100 ng/ $\mathrm{ml} \mathrm{rIFN}-\alpha$ (corresponding to ca $1.35 \times 10^{2}-1.35 \times 10^{4} \mathrm{UI} /$ $\mathrm{ml}$ ) was used in subsequent experiments. An increase of IL-12p70 was detected from pR-stimulated mDCs in the presence of rIFN- $\alpha$, compared to untreated $\mathrm{pR}$-stimulated cells (Fig. 1c). This is in line with previous observations in moDCs [17]. Higher concentrations of IFN- $\alpha$ had no additive effect, indicating that only minute amounts of IFN-a are necessary to drive this effect. For rIL-12-treated pDCs, no changes in IFN- $\alpha$ production were detected, compared to untreated cells (Fig. 1d).

The expression of maturation marker CD80 and production of the pro-inflammatory cytokine TNF- $\alpha$ was thereafter investigated on cytokine-treated DCs. The presence of rIFN- $\alpha$ had a dose-dependent effect on both pR-stimulated and untreated mDCs (Fig. 1e). Already the lowest dose of rIFN- $\alpha$ significantly elevated the expression of CD80 on pR-stimulated cells, while the highest concentrations were required to mature unstimulated $\mathrm{mDCs}$. TNF- $\alpha$ levels were on the contrary not elevated by rIFN- $\alpha$ (Suppl. Figure 1a). For pDCs, rIL-12 had no maturing effect, neither on IL3-treated nor pR-stimulated cells (Fig. 1f), and no significant difference in TNF- $\alpha$ production was detected (Suppl. Figure 1b).

\section{Co-culture of $\mathrm{mDCs}$ and $\mathrm{pDCs}$ increases the maturation of $\mathrm{mDCs}$, but not $\mathrm{pDCs}$}

Next, the direct impact on co-cultured DC subsets was investigated. Autologous $\mathrm{mDCs}$ and $\mathrm{pDCs}$ were cultured either alone or in combination in a 5:1 or 1:1 ratio. The total number of cells was kept constant between the different conditions and the cells were either left untreated or stimulated with $\mathrm{pR}$ complexes overnight. An increase in expression of maturation markers CD80 and CD86 was detected for the co-cultured $\mathrm{pR}$-stimulated $\mathrm{mDCs}$, compared to $\mathrm{mDCs}$ cultured alone (Fig. 2a and Suppl. Figure 2). An increase was also observed in the untreated control, which could be due to the presence of IL-3 in the pDC culture medium. No effect was detected for the pR-treated pDCs (Fig. 2b). There were also no significant changes in TNF- $\alpha$ levels between the different conditions (Fig. 2c). When investigating the secretion of subset-specific cytokines, the ratios of IFN- $\alpha$ corresponded well with the ratio of pDCs, while the IL12 p70 levels were high also in the co-cultured conditions where the ratio of mDCs was less (Fig. 2d, e). This supports the positive effect of IFN- $\alpha$ on IL-12p70 production noted in Fig. 1c.

\section{The presence of rIFN- $a$ reduces $\mathrm{mDC}$-induced $\mathrm{T}$-cell proliferation, but increases IFN $-\gamma$ production in innate immune cells}

To evaluate the functional effect of the increased $\mathrm{mDC}$ maturation in the presence of $\operatorname{rIFN}-\alpha$, the proliferative T-cell response was investigated in a MLR setting. First, the effect of rIFN- $\alpha$ on PBLs alone was evaluated (Fig. 3a). Anti-CD3/ anti-CD28 stimulated $\mathrm{T}$ cells displayed a small decrease in proliferation for the higher concentrations. rIFN- $\alpha$ did not significantly affect IFN- $\gamma$ secretion, but a dose-dependent increase could be detected for most donors (Fig. 3b). When the PBLs were instead stimulated with mDCs activated overnight in the presence or absence of increasing concentration rIFN- $\alpha$, the dose-dependent decrease in T-cell proliferation was again observed (Fig. 3c, g). A prominent increase of IFN- $\gamma$ secretion was observed in rIFN- $\alpha$ cultures for most pR-stimulated donors, indicating that $\mathrm{rIFN}-\alpha$ promotes cytokine secretion over T-cell proliferation (Fig. 3d, g).

IFN- $\gamma$ is secreted by activated lymphocytes and acts in a feedback loop to further stimulate Th1 polarization and effector functions [32]. Since IFN- $\alpha$ is known to activate innate immune cells [10,33], the activation status of natural Killer (NK) cells and NKT cells in the presence of rIFN- $\alpha$ was investigated. PBLs were cultured overnight in the presence of increasing concentrations of $\operatorname{rIFN}-\alpha$, and the upregulation of activation marker CD69 and cell typespecific production of IFN- $\gamma$ was evaluated for T cells, NK cells, and NKT cells (Fig. 3e, f and Suppl. Figure 3). rIFN- $\alpha$ induced dose-dependent upregulation of CD69 in all cell types investigated (Fig. 3e). Furthermore, it induced IFN- $\gamma$ production by NK cells (Fig. 3f). Hence, the presence of IFN- $\alpha$-activated innate immune cells in the MLR of Fig. $3 \mathrm{c}$ might affect the observed T-cell responses.

\section{Innate immune cells are activated in the presence of pR-stimulated pDCs}

To investigate if innate immune cells also can be activated by pR-stimulated DCs, their activation status was examined upon co-culture with mDC and/or pDCs (Fig. 4). Autologous $\mathrm{mDCs}$ and $\mathrm{pDCs}$ were cultured in the same ratios as in Fig. 2 and allogeneic PBLs were added after overnight stimulation for another $24 \mathrm{~h}$. The cell type-specific expression of CD69 and IFN- $\gamma$ was thereafter investigated. Both NK cells and NKT cells upregulated CD69 after overnight co-culture with pDCs or pDCs co-cultured with mDCs (Fig. 4a). However, in the presence of $\mathrm{mDCs}$ alone, only a minor fraction of cells expressed this activation marker. Stimulated pDCs were also able to induce IFN- $\gamma$ production in innate immune 
Fig. $1 \mathrm{mDCs}$ and $\mathrm{pDCs}$ upregulate CD80 and secrete high levels of subset-specific cytokines IL-12p70 and IFN- $\alpha$, respectively, upon $\mathrm{pR}$ treatment. Purified mDCs and pDCs were stimulated overnight with medium alone/IL-3, or $\mathrm{pR}$ complexes in the presence or absence of an IFN blocking cocktail or recombinant cytokines. Average expression levels of the CD80 maturation marker \pm SEM were measured on $\mathbf{a} \mathrm{mDCs}$ and $\mathbf{b} \mathrm{pDCs}$ from five donors. Cytokine release into supernatant was analyzed with ELISA. Average secreted levels of $\mathbf{c}$ IL-12p70 \pm SEM from seven $\mathrm{pR}$-activated $\mathrm{mDC}$ donors in the presence or absence of increasing levels (1; 10 ; and $100 \mathrm{ng} / \mathrm{ml}$ ) of $\mathrm{rIFN}-\alpha$ and $\mathbf{d}$ IFN- $\alpha \pm$ SEM from nine $\mathrm{pR}$-activated $\mathrm{pDC}$ donors in the presence or absence of increasing levels $(0.2$ and $2 \mathrm{ng} / \mathrm{ml})$ of rIL-12p70. e Average MFI expression levels of CD80 \pm SEM from seven mDC donors in the presence or absence of increasing levels $(1 ; 10$; and $100 \mathrm{ng} / \mathrm{ml}$ ) of rIFN- $\alpha$. f Average MFI expression levels of CD80 \pm SEM from six pDC donors in the presence or absence of increasing levels $(0.2$ and $2 \mathrm{ng} /$ $\mathrm{ml})$ of rIL-12p70. Statistical differences compared to untreated controls were analyzed by paired one-way ANOVA with Bonferroni's multiple comparison test and significance is indicated by $*(p<0.05)$, $* *(p<0.01), * * *(p<0.001)$, or ns (non-significant)
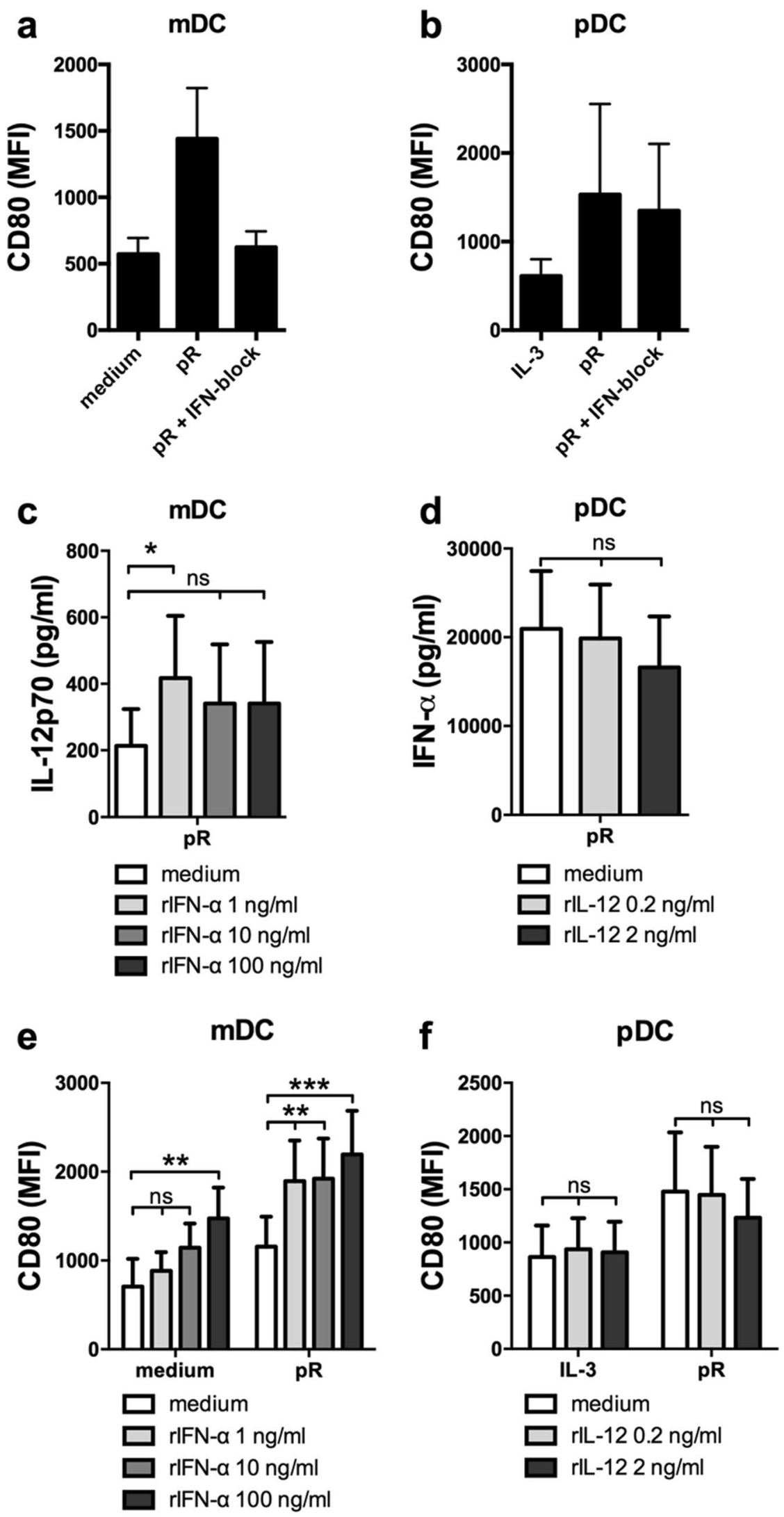

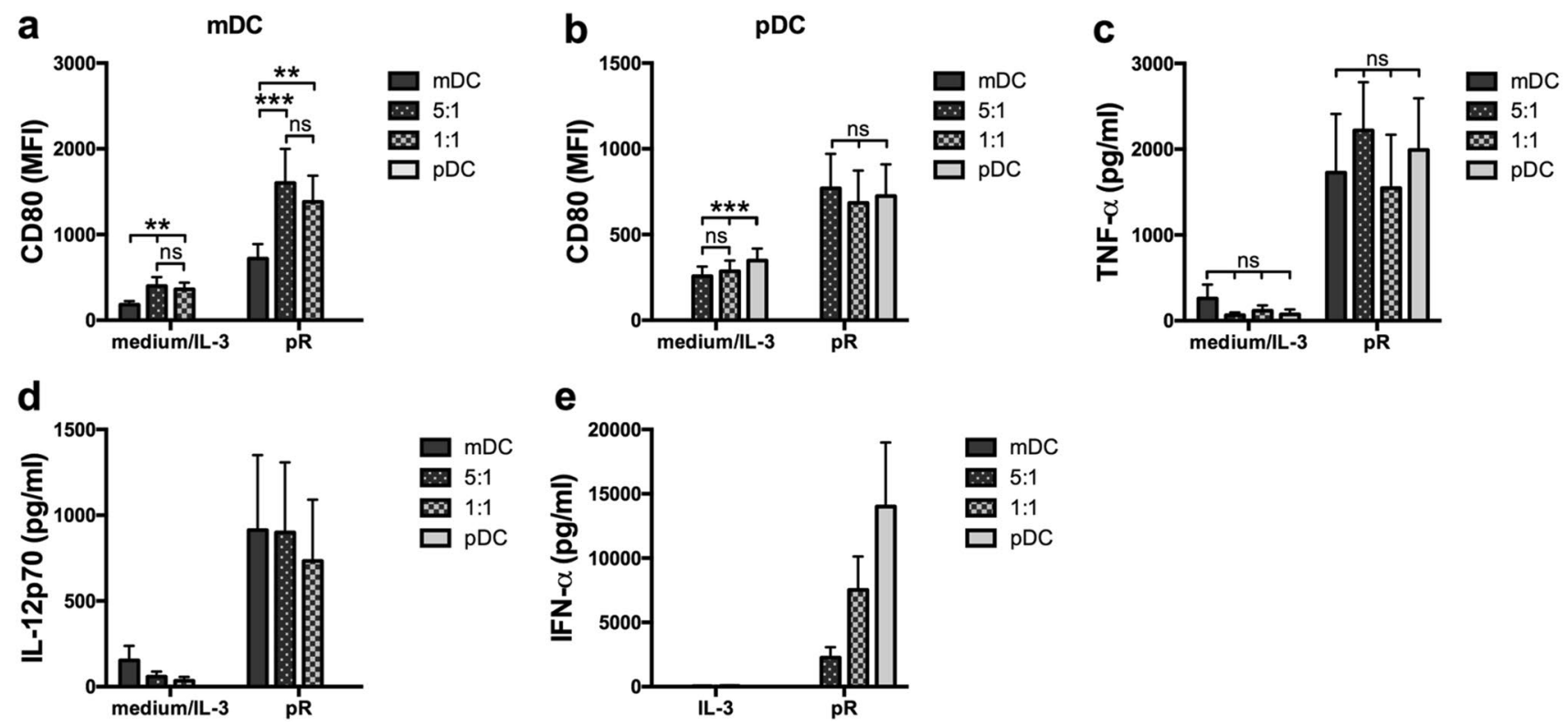

Fig. 2 Stimulation of co-cultured autologous mDCs and pDCs enhance $\mathrm{pR}$-mediated $\mathrm{mDC}$, but not $\mathrm{pDC}$, maturation. Purified autologous $\mathrm{mDCs}$ and $\mathrm{pDCs}$ were cultured overnight either alone or together in a 5:1 or 1:1 ratio in the presence of medium alone/IL-3 or $\mathrm{pR}$ complexes. The total number of cells was kept constant between the cultures. Upregulation of maturation marker CD80 was evaluated by flow cytometry. Cytokine release was analyzed with ELISA. a mDCs or $\mathbf{b}$ pDCs from 11 donors cultured either alone or combined

cells, with the highest levels being expressed in cells from the 1:1 ratio $\mathrm{mDC}-\mathrm{pDC}$ co-culture, while only background levels were detected in cells stimulated with only with $\mathrm{mDCs}$ (Fig. 4b).

\section{Soluble factors produced by $\mathrm{pR}$-stimulated pDCs reduces the proliferative response of $T$ cells}

To explore the effect of IFN- $\alpha$ and IL-12 on T-cell activation in more detail and considering the prominent effect of pDCs on innate immune cells, subsequent studies of adaptive responses were performed with isolated T cells. Allogeneic $\mathrm{T}$ cells were added to $\mathrm{pR}$-activated $\mathrm{DCs}$. $\mathrm{mDC}$ s induced a robust proliferative T-cell response. Having pDCs in the culture reduced this response (Fig. 5a, g), a pattern that was not observed for the IFN- $\gamma$ release (Fig. 5b, g).

Since rIFN- $\alpha$ in Fig. $3 \mathrm{c}$ was shown to inhibit mDCinduced T-cell proliferation, the impact of released factors from $\mathrm{pR}$-treated $\mathrm{pDC}$ was investigated on stimulated $\mathrm{T}$ cells. Conditioned medium (CM) was made by stimulating pDCs overnight with either pR complexes (pR-CM) or IL-3 (IL-3-CM), and the supernatant from several donors was collected and pooled. In the presence of pR-CM, anti-CD3/ anti-CD28-stimulated $\mathrm{T}$ cells displayed a reduced proliferative response compared to untreated activated cells (Fig. 5c). This was less prominent for cells cultured with IL-3-CM at a 5:1 or 1:1 ratio in the presence or absence of stimuli. Average secreted levels of $\mathbf{c}$ TNF- $\alpha \pm$ SEM from eight donors, $\mathbf{d}$ IL-12p70 \pm SEM from seven donors, and e IFN $-\alpha \pm$ SEM from ten donors. Statistical differences within the treatment groups were analyzed by paired one-way ANOVA with Bonferroni's multiple comparison test and significance is indicated by $* *(p<0.01), * * *(p<0.001)$, or ns (nonsignificant)

or $\mathrm{pR}$ complexes. In a similar manner, the mDC-induced $\mathrm{T}$-cell proliferation was markedly less in the presence of $\mathrm{pR}-\mathrm{CM}$ than of IL-3-CM or untreated pR-stimulated mDCs (Fig. 5d), despite that pR-CM-treated pR-stimulated mDCs expressed higher levels of maturation markers than $\mathrm{pR}$ treatment alone (Suppl. Figure 4a). The involvement of IFN- $\alpha$ in the reduced proliferative response was confirmed by adding the cytokine to pR-stimulated mDCs together with the allogeneic T cells (Suppl. Figure 4b). To circumvent the observed inhibitory effect of IFN- $\alpha$ on T-cell proliferation, the DC cultures were thoroughly washed just before the addition of allogeneic $\mathrm{T}$ cells. This increased the proliferative response of $\mathrm{T}$ cells activated by $\mathrm{mDCs}$ co-cultured with pDCs, but reduced IFN- $\gamma$ secretion (Fig. 5e, f).

\section{Discussion}

In this study, we have investigated the effect of type I IFNs on human blood-derived $\mathrm{mDC}$ maturation and function. This is an important question in light of clinical treatment modalities involving type I IFNs and agents stimulating high levels of it. However, the answers found in literature are partly contradictory, where the addition of type I IFNs to myeloid DCs has been shown to both inhibit [18-20] and promote [17, 21, 22] IL-12p70 production, and mostly does not investigate the 
effect of naturally produced type I IFNs but rely on selected recombinant proteins.

We here demonstrate that IFN- $\alpha$ has a beneficial impact on mDC maturation and IL-12p70 production, but impair T-cell proliferation, while recombinant IL-12p70 had no effect on pDC maturation or cytokine production. Type I IFN signaling is required for $\mathrm{pR}$-mediated $\mathrm{mDC}$ maturation, since blocking experiments abolished the upregulation of maturation markers. Adding rIFN- $\alpha$ to $\mathrm{mDCs}$ significantly enhanced pR-induced IL-12p70 release, corresponding to previous observations in murine bone marrow-derived DCs [17] and human moDCs [17, 21, 22]. However, type I IFNs alone do not provoke IL-12 production, but need to be combined with an IL-12p70-inducing stimulus [21, 34]. This, on the other hand, does not hold true for DC maturation. When treating unstimulated $\mathrm{mDCs}$ with increasing doses of rIFN- $\alpha$, we observed that the highest dose used results in an even higher expression of maturation markers than for $\mathrm{pR}$ stimulated DCs. The ability of type I IFNs to mature DCs is supported by literature [23, 34-36].

The presence of pDCs strongly enhanced the maturation response of $\mathrm{mDCs}$ in $\mathrm{pR}$-activated co-cultures. In addition, despite reduced total numbers of mDCs, the IL-12p70 secretion remained high in the co-cultures, indicating an increased capacity of the co-cultured $\mathrm{mDCs}$ to produce IL$12 \mathrm{p} 70$. For $\mathrm{pDCs}$, the production of IFN- $\alpha$ correlated much stricter with the total number of cells in the culture. Several studies on $\mathrm{mDC}-\mathrm{pDC}$ crosstalk have highlighted the importance of pDCs to fully potentiate the mDCs [14]. Both cell-cell interaction and secreted factors have been described as mediators of this crosstalk, but type I IFNs emerge as a key factor $[15,37,38]$. Confirming the stimulatory ability of pDC-secreted factors, we could induce a strong maturation response in $\mathrm{mDCs}$ treated with conditioned medium from $\mathrm{pR}$-activated $\mathrm{pDCs}$. However, since $\mathrm{pR}$ complexes mature both pDCs and $\mathrm{mDCs}$, we cannot fully exclude that this effect is not partly due to remaining complexes in the supernatant, although $\mathrm{pR}$ complexes incubated overnight are strongly reduced in their stimulatory ability (data not shown) and their half-time is reportedly a few hours [27].

Type I IFNs have been shown to polarize a Th1 response in naïve T cells [39], although it is questioned whether they fully can substitute the effect of IL-12p70 or if additional cytokine signaling is needed [40, 41]. An elegant study by Ramos et al. suggested that IFN- $\alpha$ and IL- 12 p70 induce varied effector functions in stimulated $\mathrm{CD} 8^{+} \mathrm{T}$ cells, where IL12 p70 signaling promoted fast dividing $\mathrm{T}$ cells with an effector-memory phenotype. IFN- $\alpha$, on the other hand, reduced proliferation in responding cells and rather stimulated a central-memory phenotype [42]. Importantly, the strength of the T-cell receptor signaling determine which phenotype predominantly develops [42-44], possibly explaining the distinct reduction in T-cell proliferation we observe in MLRs with IFN- $\alpha$ - or pR-CM-treated mDCs, but much less when $\mathrm{T}$ cells are stimulated with anti-CD3/anti-CD28 beads. One could speculate that reducing the dose of the highly stimulatory activation beads would make the T cells more sensitive to the polarizing effect of type I IFNs and hence render a similar dose-response pattern as in the MLRs. Further support of the IFN- $\alpha$-mediated polarization is found in a recent study by Willemen et al., where moDCs engineered to secrete high levels of IFN- $\alpha$ had a reducing effect on both $\mathrm{CD} 4^{+}$and $\mathrm{CD} 8^{+}$T-cell proliferations in an IFN- $\alpha$-dependent manner. Interestingly, antigen-specific T-cell activation and IFN- $\gamma$ production was markedly increased in the presence of IFN- $\alpha$, despite their reduced proliferative response [33]. This correlates well with our observations of a reduced proliferative T-cell response but increased IFN- $\gamma$ secretion in MLRs with co-cultured DCs. In addition, thorough washing of cocultured DCs before addition of allogeneic $T$ cells increased the T-cell proliferation, but reduced IFN- $\gamma$ production, further supporting the direct effect of type I IFNs on T cells.

Although washing the DC cultures increases T-cell proliferation, removing the secreted factors does not fully restore the proliferative response induced by $\mathrm{mDCs}$ alone. This might be explained by a reduced total number of $\mathrm{mDCs}$, since pR-stimulated pDCs are modest inducers of T-cell proliferation, but it might also be a symptom of the enhanced maturation response detected for $\mathrm{mDCs}$ in the co-cultures. Washing also removes the elevated levels of pro-inflammatory cytokines and IL-12p70 from the culture and due to the late kinetics of 24-h activation, these factors are not replaced. Several studies supporting the IFN- $\alpha$-mediated enhancement of IL-12-production also indicate a time dependence for this effect, where addition of type I IFNs at a later point in $\mathrm{mDC}$ maturation inhibits further production of IL-12p70 [20, 21]. Hence, an earlier wash of the DC cultures and addition of isolated $\mathrm{T}$ cells would likely be more beneficial.

In this study, we have investigated two different ratios of $\mathrm{mDC}-\mathrm{pDC}$ co-culture. However, surprisingly few differences between the groups are detected. Even a low number of pDCs can significantly enhance $\mathrm{mDC}$ maturation and affect T-cell proliferation and activation. Indeed, the only set-up where an equal ratio between $\mathrm{mDC}$ and $\mathrm{pDCs}$ was beneficial was when studying the innate immune cell activation. IFN- $\alpha$ alone had the ability to activate NK cells in a dose-dependent manner, and stimulated pDCs induced an even greater effect. Stimulated mDCs alone, however, were poor inducers of innate immune cell activation, even though IL-12p70 is a known activator of both NK and NKT cells $[45,46]$, and the presence of pDCs was required to upregulate the activation marker CD69. However, pDCs alone were not sufficient to significantly increase IFN- $\gamma$ production in innate immune cells. Instead, the 1:1 combination with mDCs was necessary to induce peak activation of both NK and NKT cells. In this culture, the IFN- $\alpha$ levels are still high, 

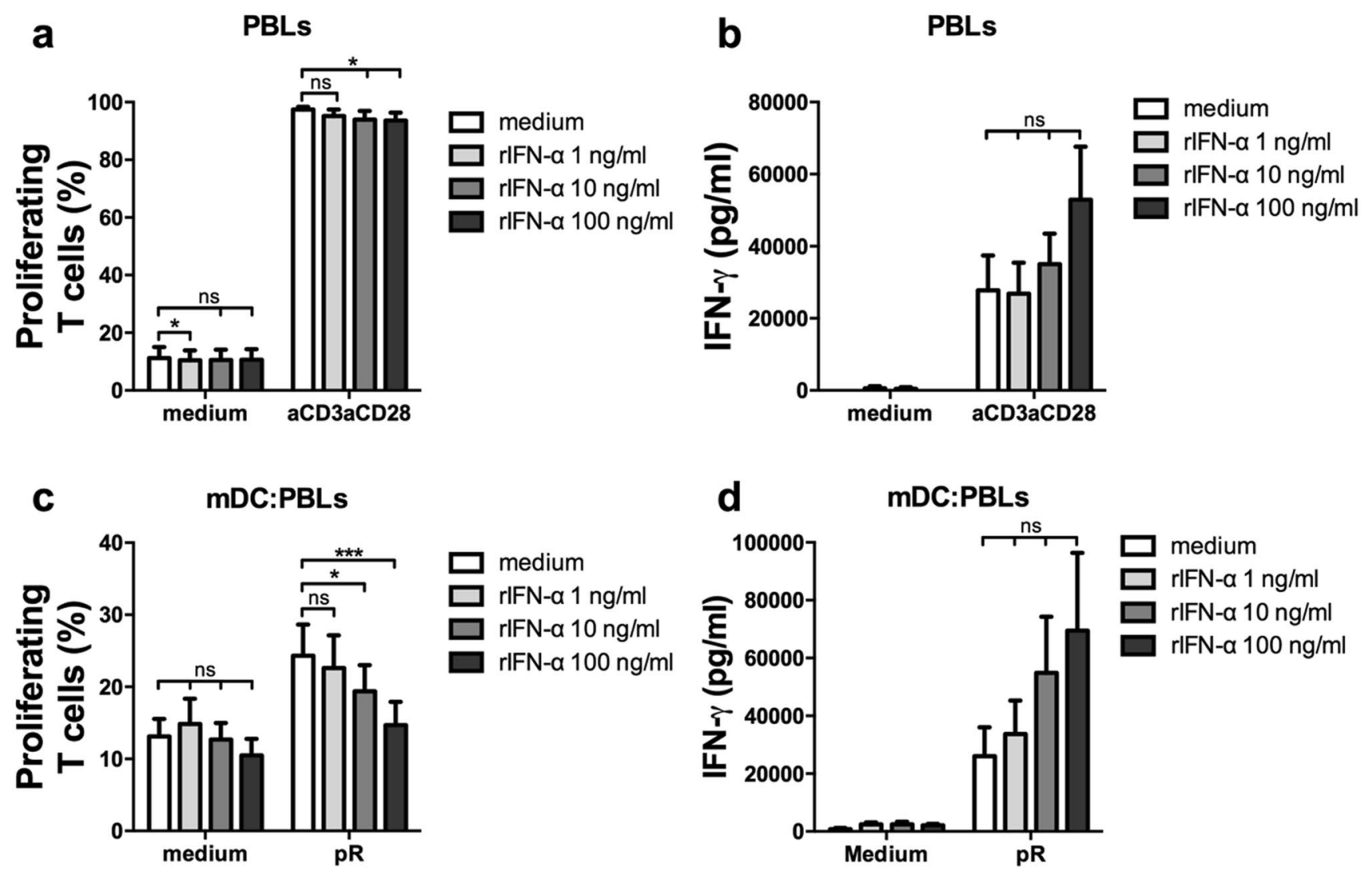

e

PBLs

f

PBLs
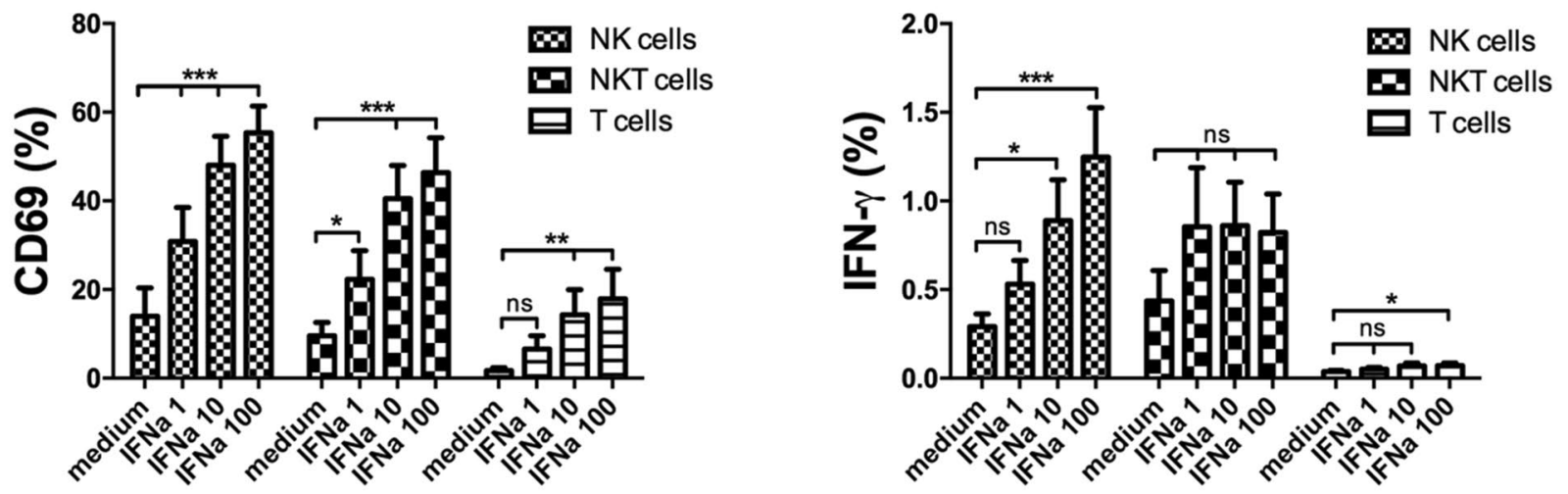

g

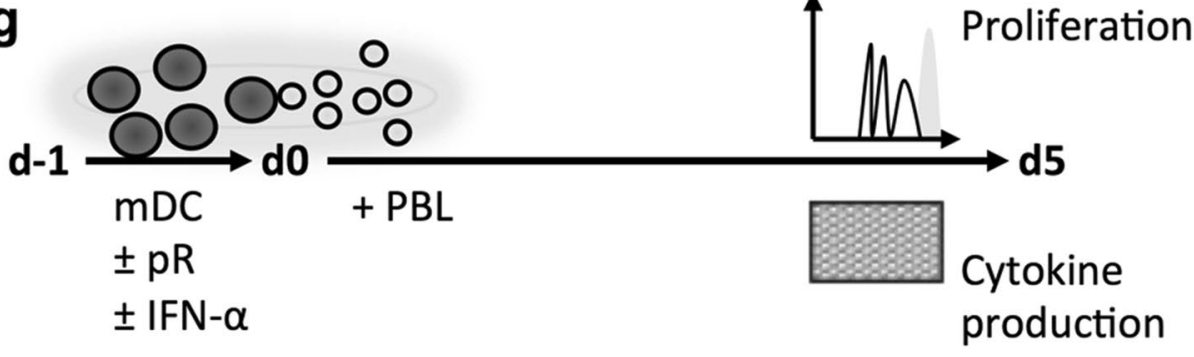


4Fig. 3 IFN- $\alpha$ reduces T-cell proliferation but activates innate immune cells and increases the production of IFN- $\gamma$. PBLs were activated by anti-CD3/anti-CD28 beads or matured allogeneic mDCs in the presence or absence of increasing levels (1; 10; and $100 \mathrm{ng} / \mathrm{ml}) \mathrm{rIFN}-\alpha$ and the proliferative responses of T cells, or activation of NK, NKT, and $\mathrm{T}$ cells were measured by flow cytometry. The release of IFN- $\gamma$ was measured with ELISA. a Mean percentage \pm SEM proliferating $\mathrm{T}$ cells from nine PBL donors at day 5 of culture. $\mathbf{b}$ Mean levels of secreted IFN $-\gamma \pm$ SEM from nine PBL donors at day 4 of culture. c Mean percentage \pm SEM of proliferating T cells at day 5 induced by nine mDC donors. d Mean levels of secreted IFN- $\gamma \pm$ SEM at day 4 of co-culture induced by five $\mathrm{mDC}$ donors. Mean percentage \pm SEM NK, NKT, or T cells expressing e the activation marker CD69 or $\mathbf{f}$ intracellular IFN- $\gamma$ after overnight treatment in the presence or absence of increasing levels $(1 ; 10$; and $100 \mathrm{ng} / \mathrm{ml}) \mathrm{rIFN}-\alpha$ from nine PBL donors. g Illustrative drawing of experimental set-up. Statistical differences compared to untreated controls within each treatment group or for each investigated cell type were analyzed by paired oneway ANOVA with Bonferroni's multiple comparison test and significance is indicated by $*(p<0.05), * *(p<0.01), * * *(p<0.001)$, or ns (non-significant)

while IL-12p70 is also present, which implies that synergistic effects on innate immune activation can be achieved by combining the two DC subsets and thereby supplying both IFN- $\alpha$ and IL-12p70. Nevertheless, innate immune cells have been shown to respond to several other factors provided by activated DCs [10], and we have not excluded the involvement of additional factors in this crosstalk.

To conclude, we here confirm previous studies describing beneficial effects of type I IFNs on mDC maturation and IL-12p70 production [17, 21, 22]. We additionally show that activated type I IFN-producing pDCs also have this effect on $\mathrm{mDCs}$ and are highly beneficial for the activation of innate immune cells. The observed reduced proliferative response of T cells stimulated by co-cultured DCs is mostly dependent on the inhibitory effect of secreted factors, rather than a reduced stimulatory effect of co-cultured mDCs. This might explain why some studies have ascribed type I IFNs a negative effect on the functionality of mDCs [18, 20,21]. It also indicates that ex vivo-stimulated DCs will still be functional in vivo if the cells are stimulated for a shorter time and washed before administration to the patient. The ratio between the co-cultured DC subsets is less important for the functional effects, and even a minor fraction of activated pDCs has a positive effect on both innate immune cell and T-cell activations. Indeed, melanoma patients treated with a pDC-based cellular vaccine displayed an IFN signature,
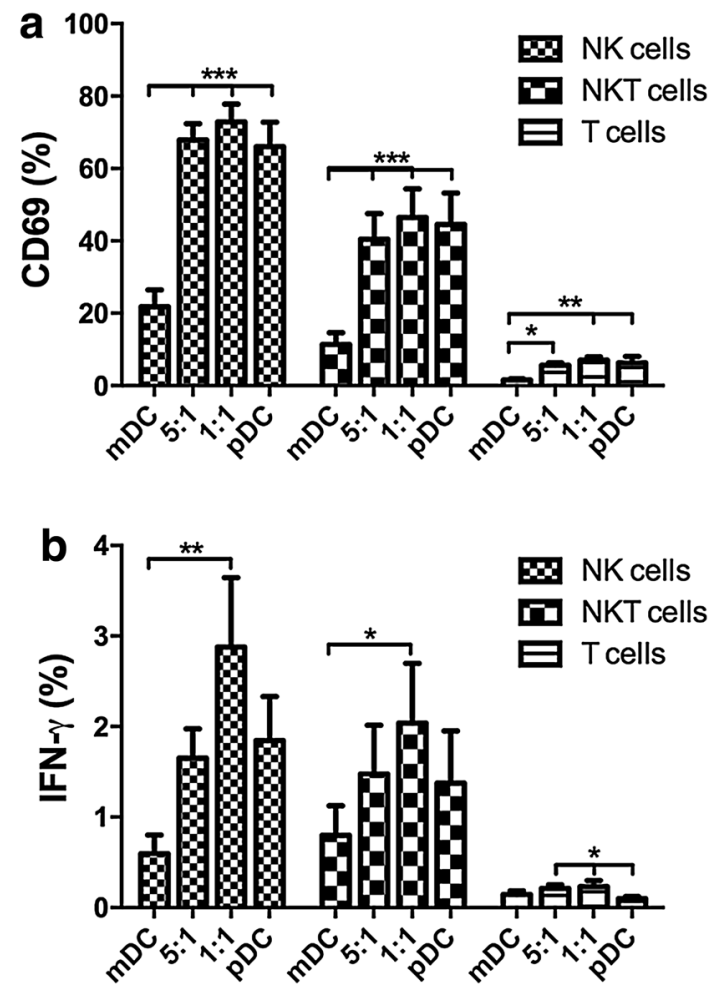

Fig. 4 pR-activated pDCs, but not mDCs, are able to activate innate immune cells. $\mathrm{mDCs}$ and $\mathrm{pDCs}$ were $\mathrm{pR}$-activated overnight, either alone or in $5: 1$ or $1: 1$ ratios and thereafter co-cultured another $24 \mathrm{~h}$ with allogeneic PBLs, whereafter the upregulation of activation marker CD69 and cell type-specific IFN- $\gamma$ production was determined by flow cytometry. Mean expression \pm SEM of a CD69 and b IFN- $\gamma$ from six PBL donors was determined. Statistical differences compared within cell type were analyzed by paired one-way ANOVA with Bonferroni's multiple comparison test and significance is indicated by $*(p<0.05), * *(p<0.01), * * *(p<0.001)$. All unlabeled comparisons were statistically non-significant

which even was detected in patients receiving the lowest dose cells, indicating that stimulated human pDCs are highly potent also in vivo [4]. Since pDCs are less prevalent than mDCs in human blood, we conclude that cellular immunotherapies based on both primary DC subsets can utilize all cells isolated, despite a lower ratio of pDCs, and still be predicted highly functional. 
Fig. 5 Secreted factors from $\mathrm{pR}$-activated $\mathrm{pDCs}$ reduce the proliferation of stimulated $\mathrm{T}$ cells but increase their ability to produce IFN- $\gamma$. T cells were stimulated with overnightactivated $\mathrm{mDCs}$ and $\mathrm{pDCs}$, cultured either alone or in 5:1 or 1:1 ratios, or with anti-CD3/ anti-CD28 beads in the presence of indicated stimuli. The proliferative responses were investigated after 5 days by flow cytometry. Secretion of IFN- $\gamma$ at day 4 was measured by ELISA. a Mean percentage \pm SEM proliferating $\mathrm{T}$ cells induced by six DC donors. b Mean levels of secreted IFN- $\gamma \pm$ SEM from seven DC donors at day 4 of culture. c Mean percentage \pm SEM proliferating anti-CD3/ anti-CD28-activated $\mathrm{T}$ cells treated with medium alone, pR-CM, IL-3-CM, or freshly made $\mathrm{pR}$ complexes from six donors. d Mean percentage \pm SEM proliferating $\mathrm{T}$ cells induced by three to seven $\mathrm{mDC}$ donors in the presence of medium alone, $\mathrm{pR}-\mathrm{CM}$, or IL-3-CM. e Mean percentage \pm SEM proliferating T cells induced by six DC donors that were washed three times before addition of T cells. $\mathbf{f}$ Mean levels of secreted IFN- $\gamma \pm$ SEM at day 4 from seven washed DC donors. $\mathbf{g}$ Illustrative drawing of experimental set-up. Statistical differences were analyzed by paired one-way ANOVA or, for (d), ordinary ANOVA with Bonferroni's multiple comparison test and significance is indicated by $*(p<0.05)$, $* *(p<0.01), * * *(p<0.001)$, or ns (non-significant). All unlabeled comparisons in figures $\mathbf{a}, \mathbf{b}, \mathbf{e}$, and $\mathbf{f}$ were statistically non-significant
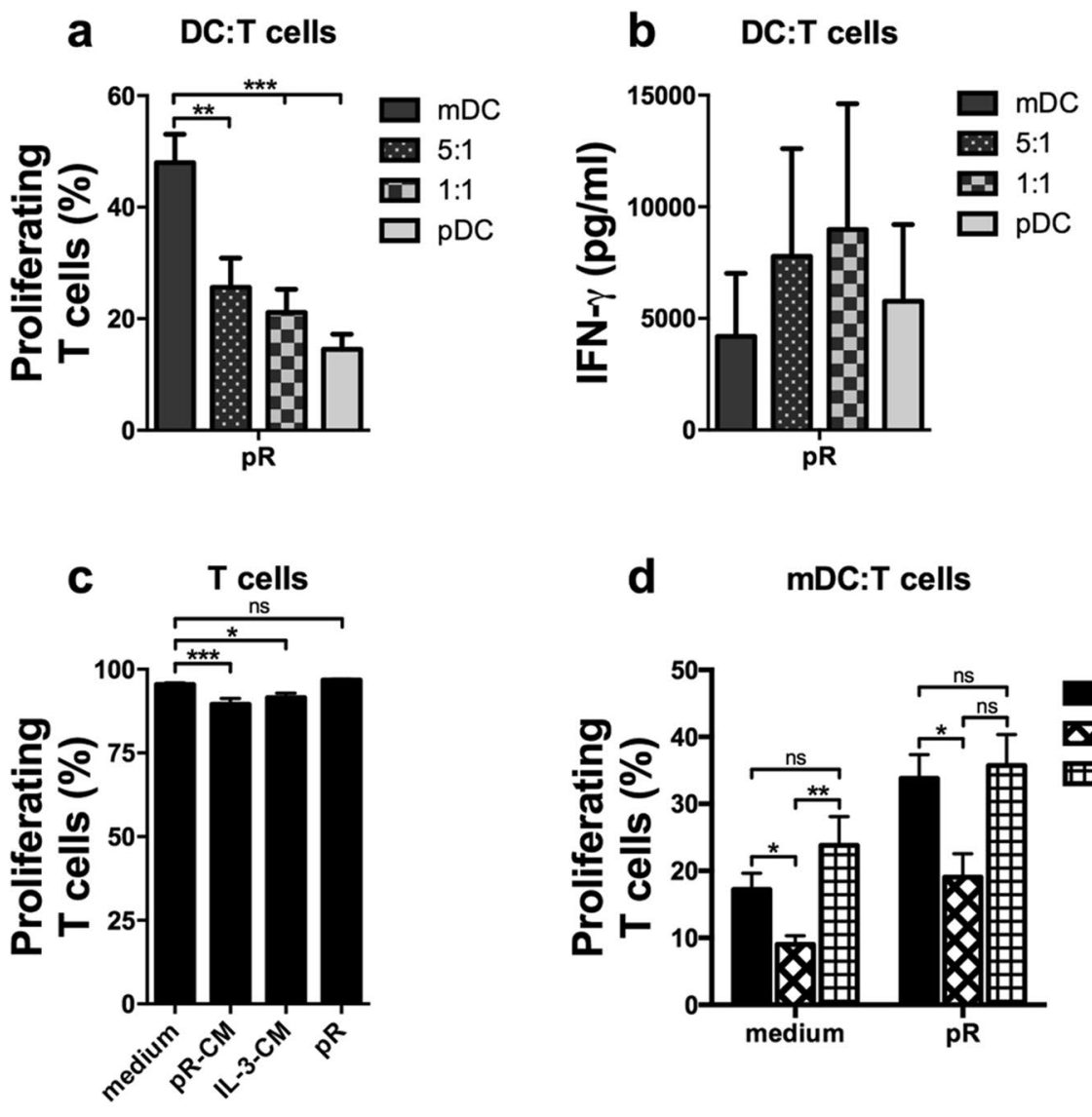

d
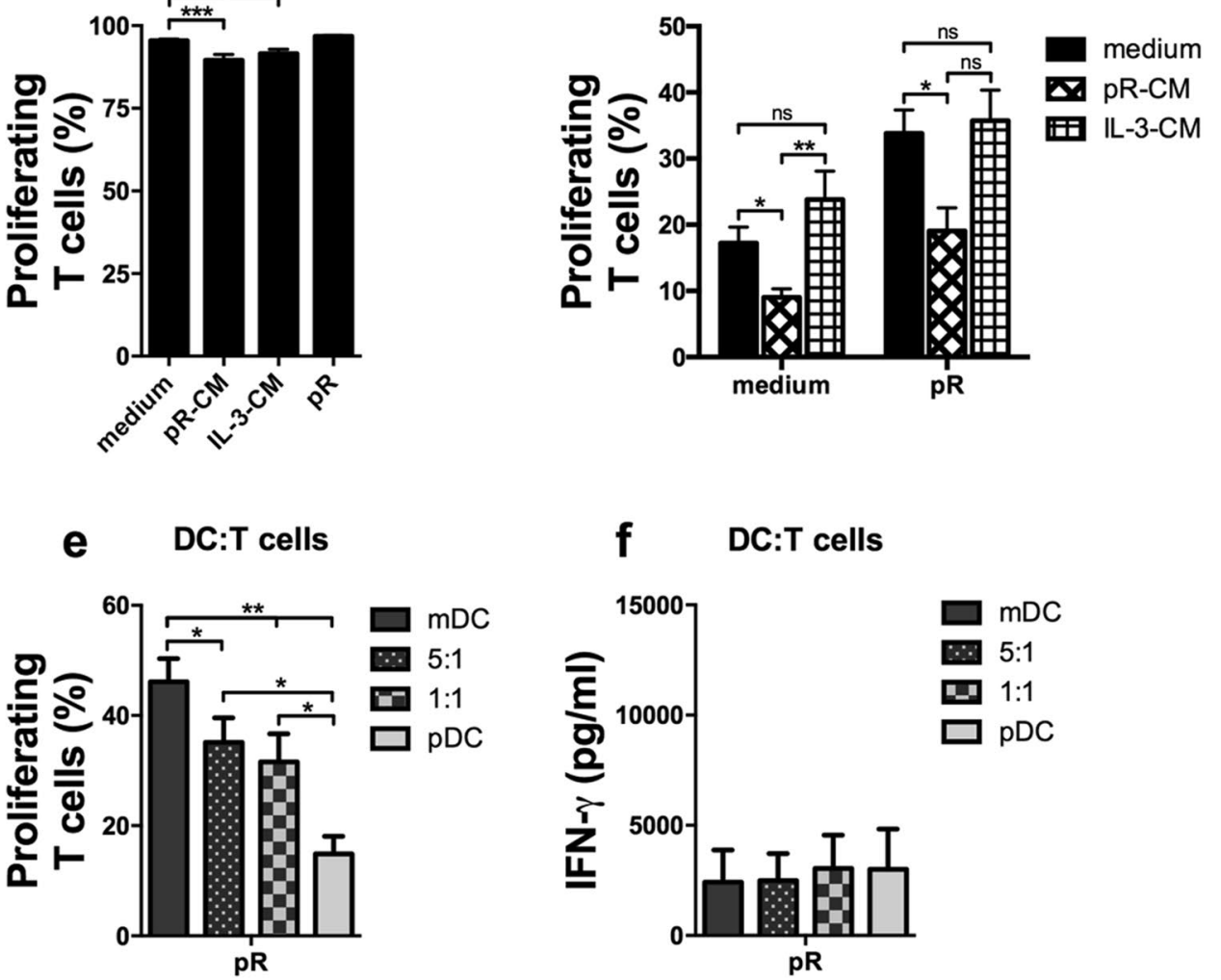

Author contributions AES designed and performed research, analyzed data, and wrote the manuscript; TSMM, JJPB, and MDB contributed to experimental design, performed research, and analyzed data; GF-G, and SPS contributed to experimental design and performed research; FW, GB, and GS contributed to experimental design; IJMV supervised the study and contributed to experimental design. 
Funding This study was supported by the Swedish Research Council and the Netherlands Organization for Scientific Research (NWO-Vici 91814655 and NWO-ZonMW 95103002).

\section{Compliance with ethical standards}

Conflict of interest All authors of this paper declare that they have no conflict of interest.

Ethical approval and ethical standards Human cells were obtained from blood products from randomized healthy blood donors who have given informed consent according to institutional guidelines. No ethical permit is needed for the usage of buffy coats.

Open Access This article is distributed under the terms of the Creative Commons Attribution 4.0 International License (http://creativeco mmons.org/licenses/by/4.0/), which permits unrestricted use, distribution, and reproduction in any medium, provided you give appropriate credit to the original author(s) and the source, provide a link to the Creative Commons license, and indicate if changes were made.

\section{References}

1. O'Keeffe M, Mok WH, Radford KJ (2015) Human dendritic cell subsets and function in health and disease. Cell Mol Life Sci 72:4309-4325

2. Wimmers F, Schreibelt G, Sköld AE, Figdor CG, De Vries IJ (2014) Paradigm shift in dendritic cell-based immunotherapy: from in vitro generated monocyte-derived DCs to naturally circulating DC subsets. Front Immunol 5:165

3. Constantino J, Gomes C, Falcão A, Cruz MT, Neves BM (2016) Antitumor dendritic cell-based vaccines: lessons from 20 years of clinical trials and future perspectives. Transl Res 168:74-95

4. Tel J, Aarntzen EH, Baba T, Schreibelt G, Schulte BM, BenitezRibas D, Boerman OC, Croockewit S, Oyen WJ, van Rossum M, Winkels G, Coulie PG, Punt CJ, Figdor CG, de Vries IJ (2013) Natural human plasmacytoid dendritic cells induce antigenspecific T-cell responses in melanoma patients. Cancer Res 73:1063-1075

5. Schreibelt G, Bol KF, Westdorp H, Wimmers F, Aarntzen EH, Duiveman-de Boer T, van de Rakt MW, Scharenborg NM, de Boer AJ, Pots JM, Olde Nordkamp MA, van Oorschot TG, Tel J, Winkels G, Petry K, Blokx WA, van Rossum MM, Welzen ME, Mus RD, Croockewit SA, Koornstra RH, Jacobs JF, Kelderman S, Blank CU, Gerritsen WR, Punt CJ, Figdor CG, de Vries IJ (2016) Effective clinical responses in metastatic melanoma patients after vaccination with primary myeloid dendritic cells. Clin Cancer Res 22:2155-2166

6. Halilovic A, Bol KF (2016) The use of dendritic cell vaccinations in melanoma: where are we now? Melanoma Manag 3:247-250

7. Sittig S, de Vries J, Schreibelt G (2015) Primary human blood dendritic cells for cancer immunotherapy-tailoring the immune response by dendritic cell maturation. Biomedicines 3:282-303

8. Theofilopoulos A, Baccala R, Beutler B, Kono D (2005) Type I interferons (alpha/beta) in immunity and autoimmunity. Annu Rev Immunol 23:307-336

9. Kranz LM, Diken M, Haas H, Kreiter S, Loquai C, Reuter KC, Meng M, Fritz D, Vascotto F, Hefesha H, Grunwitz C, Vormehr M, Hüsemann Y, Selmi A, Kuhn AN, Buck J, Derhovanessian E, Rae R, Attig S, Diekmann J, Jabulowsky RA, Heesch S, Hassel J, Langguth P, Grabbe S, Huber C, Türeci Ö, Sahin U (2016)
Systemic RNA delivery to dendritic cells exploits antiviral defence for cancer immunotherapy. Nature 534:396-401

10. Van Beek JJ, Wimmers F, Hato SV, de Vries IJ, Sköld AE (2014) Dendritic cell cross talk with innate and innate-like effector cells in antitumor immunity: implications for DC vaccination. Crit Rev Immunol 34:517-536

11. Steinman RM (1996) Dendritic cells and immune-based therapies. Exp Hematol 24:859-862

12. Piccioli D, Sammicheli C, Tavarini S, Nuti S, Frigimelica E, Manetti AG, Nuccitelli A, Aprea S, Valentini S, Borgogni E, Wack A, Valiante NM (2009) Human plasmacytoid dendritic cells are unresponsive to bacterial stimulation and require a novel type of cooperation with myeloid dendritic cells for maturation. Blood 113:4232-4239

13. Kreutz M, Bakdash G, Dolen Y, Sköld AE, van Hout-Kuijer MA, de Vries IJ, Figdor CG (2015) Type I IFN-mediated synergistic activation of mouse and human DC subsets by TLR agonists. Eur J Immunol 45:2798-2809

14. Bakdash G, Schreurs I, Schreibelt G, Tel J (2014) Crosstalk between dendritic cell subsets and implications for dendritic cell-based anticancer immunotherapy. Expert Rev Clin Immunol 10:915-926

15. Lou Y, Liu C, Kim GJ, Liu YJ, Hwu P, Wang G (2007) Plasmacytoid dendritic cells synergize with myeloid dendritic cells in the induction of antigen-specific antitumor immune responses. J Immunol 178:1534-1541

16. Stifter S, Bhattacharyya N, Pillay R, Flórido M, Triccas J, Britton W, Feng C (2016) Functional interplay between Type I and II interferons is essential to limit influenza A virus-induced tissue inflammation. Plos Pathog 12:e1005378

17. Gautier G, Humbert M, Deauvieau F, Scuiller M, Hiscott J, Bates E, Trinchieri G, Caux C, Garrone P (2005) A type I interferon autocrine-paracrine loop is involved in Toll-like receptorinduced interleukin-12p70 secretion by dendritic cells. J Exp Med 201:1435-1446

18. McRae BL, Semnani RT, Hayes MP, van Seventer GA (1998) Type I IFNs inhibit human dendritic cell IL-12 production and Th1 cell development. J Immunol 160:4298-4304

19. Ito $T$, Amakawa $R$, Inaba $M$, Ikehara $S$, Inaba K, Fukuhara $S$ (2001) Differential regulation of human blood dendritic cell subsets by IFNs. J Immunol 166:2961-2969

20. Yen J-H, Kong W, Hooper K, Emig F, Rahbari K, Kuo P-C, Scofield B, Ganea D (2015) Differential effects of IFN- $\beta$ on IL-12, IL-23, and IL-10 expression in TLR-stimulated dendritic cells. J Leukoc Biol 98:689-702

21. Heystek H, den Drijver M, Kapsenberg RA, van Lier, de Jong E (2003) Type I IFNs differentially modulate IL-12p70 production by human dendritic cells depending on the maturation status of the cells and counteract IFN- $\gamma$-mediated signaling. Clin Immunol 107:170-177

22. Luft T, Luetjens P, Hochrein H, Toy T (2002) IFN- $\alpha$ enhances CD40 ligand-mediated activation of immature monocytederived dendritic cells. Int Immunol 14:367-380

23. Tough D (2004) Type I interferon as a link between innate and adaptive immunity through dendritic cell stimulation. Leuk Lymphoma 45:257-264

24. Montoya M, Schiavoni G, Mattei F, Gresser I, Belardelli F, Borrow P, Tough DF (2002) Type I interferons produced by dendritic cells promote their phenotypic and functional activation. Blood. 99: 3263-3271

25. Sköld AE, van Beek JJ, Sittig SP, Bakdash G, Tel J, Schreibelt G, de Vries IJ (2015) Protamine-stabilized RNA as an ex vivo stimulant of primary human dendritic cell subsets. Cancer Immunol Immunother 64:1461-1473

26. Scheel B, Teufel R, Probst J, Carralot J-P, Geginat J, Radsak M, Jarrossay D, Wagner H, Jung G, Rammensee H-G, Hoerr 
I, Pascolo S (2005) Toll-like receptor-dependent activation of several human blood cell types by protamine-condensed mRNA. Eur J Immunol 35:1557-1566

27. Rettig L, Haen S, Bittermann A, von Boehmer L, Curioni A, Krämer S, Knuth A, Pascolo S (2010) Particle size and activation threshold: a new dimension of danger signaling. Blood 115:4533-4541

28. Mathan TS, Textor J, Sköld AE, Reinieren-Beeren I, van Oorschot T, Brüning M, Figdor CG, Buschow SI, Bakdash G, de Vries IJ (2017) Harnessing RNA sequencing for global, unbiased evaluation of two new adjuvants for dendritic-cell immunotherapy. Oncotarget 8:19879-19893

29. Sköld AE, Hasan M, Vargas L, Saidi H, Bosquet N, Le Grand R, Smith CI, Spetz A-LL (2012) Single-stranded DNA oligonucleotides inhibit TLR3-mediated responses in human monocytederived dendritic cells and in vivo in cynomolgus macaques. Blood 120:768-777

30. Noppert S, Fitzgerald K, Hertzog P (2007) The role of type I interferons in TLR responses. Immunol Cell Biol 85:446-457

31. Weide B, Pascolo S, Scheel B, Derhovanessian E, Pflugfelder A, Eigentler TK, Pawelec G, Hoerr I, Rammensee HG, Garbe C (2009) Direct injection of protamine-protected mRNA: results of a phase $1 / 2$ vaccination trial in metastatic melanoma patients. J Immunother 32:498-507

32. De Jong EC, Smits HH, Kapsenberg ML (2005) Dendritic cellmediated $\mathrm{T}$ cell polarization. Springer Semin Immunopathol 26:289-307

33. Willemen Y, Van den Bergh JM, Lion E, Anguille S, Roelandts VA, Van Acker HH, Heynderickx SD, Stein BM, Peeters M, Figdor CG, Van Tendeloo VF, de Vries IJ, Adema GJ, Berneman ZN, Smits EL (2015) Engineering monocyte-derived dendritic cells to secrete interferon- $\alpha$ enhances their ability to promote adaptive and innate anti-tumor immune effector functions. Cancer Immunol Immunother 64:831-842

34. Mohanram V, Sköld AE, Bächle SM, Pathak SK, Spetz A-LL (2013) IFN- $\alpha$ induces APOBEC3G, F, and A in immature dendritic cells and limits HIV-1 spread to CD4 + T cells. J Immunol 190:3346-3353

35. Gallucci S, Lolkema M, Matzinger P (1999) Natural adjuvants: endogenous activators of dendritic cells. Nat Med 5:1249-1255

36. Van Beek JJ, Gorris MA, Sköld AE, Hatipoglu I, Van Acker HH, Smits EL, de Vries IJ, Bakdash G (2016) Human blood myeloid and plasmacytoid dendritic cells cross activate each other and synergize in inducing NK cell cytotoxicity. Oncoimmunology 5:e1227902

37. Fonteneau J-FF, Larsson M, Beignon A-SS, McKenna K, Dasilva I, Amara A, Liu Y-JJ, Lifson JD, Littman DR, Bhardwaj N (2004) Human immunodeficiency virus type 1 activates plasmacytoid dendritic cells and concomitantly induces the bystander maturation of myeloid dendritic cells. J Virol 78:5223-5232

38. Yoneyama H, Matsuno K, Toda E, Nishiwaki T, Matsuo N, Nakano A, Narumi S, Lu B, Gerard C, Ishikawa S, Matsushima K (2005) Plasmacytoid DCs help lymph node DCs to induce antiHSV CTLs. J Exp Med 202:425-435

39. Hibbert L, Pflanz S, de Malefyt WR (2003) IL-27 and IFN- $\alpha$ signal via Stat 1 and Stat 3 and induce T-Bet and IL-12R $\beta 2$ in naive $\mathrm{T}$ cells. J Interferon Cytokine Res 23:513-522

40. Van Boxel-Dezaire AHH, Rani MR, Stark GR (2006) Complex modulation of cell type-specific signaling in response to type I interferons. Immunity 25:361-372

41. Ramos HJ, Davis AM, George TC, Farrar JD (2007) IFN-alpha is not sufficient to drive Th1 development due to lack of stable T-bet expression. J Immunol 179:3792-3803

42. Ramos H, Davis A, Cole A, Schatzle J, Forman J, Farrar JD (2009) Reciprocal responsiveness to interleukin-12 and interferon-alpha specifies human CD8 + effector versus central memory T-cell fates. Blood 113:5516-5525

43. Usharauli D, Kamala T (2008) Brief antigenic stimulation generates effector CD8 T cells with low cytotoxic activity and high IL-2 production. J Immunol 180:4507-4513

44. De Beuckelaer A, Grooten J, De Koker S (2017) Type I interferons modulate CD8(+) T cell immunity to mRNA vaccines. Trends Mol Med 23:216-226

45. Nguyen KB, Salazar-Mather TP, Dalod MY, Van Deusen JB, Wei XQ, Liew FY, Caligiuri MA, Durbin JE, Biron CA (2002) Coordinated and distinct roles for IFN-alpha beta, IL-12, and IL-15 regulation of NK cell responses to viral infection. J Immunol 169:4279-4287

46. Brigl M, Bry L, Kent SC, Gumperz JE, Brenner MB (2003) Mechanism of CD1d-restricted natural killer $\mathrm{T}$ cell activation during microbial infection. Nat Immunol 4:1230-1237 